\section{Global climate stabilisation by chemical weathering during the Hirnantian glaciation}

P.A.E. Pogge von Strandmann ${ }^{1 *}$, A. Desrochers ${ }^{2}$ M.J. Murphy ${ }^{3}$, A.J. Finlay, ${ }^{4,5}$, D. Selby ${ }^{6}$, T.M. Lenton

\section{Abstract}

\section{doi: 10.7185/geochemlet.1726}

Chemical weathering of silicate rocks is a primary drawdown mechanism of atmospheric carbon dioxide. The processes that affect weathering are therefore central in controlling global climate. A temperature-controlled "weathering thermostat" has long been proposed in stabilising long-term climate, but without definitive evidence from the geologic record. Here we use lithium isotopes $\left(\delta^{7} \mathrm{Li}\right)$ to assess the impact of silicate weathering across a significant climate-cooling period, the end-Ordovician Hirnantian glaciation ( $445 \mathrm{Ma})$. We find a positive $\delta^{7} \mathrm{Li}$ excursion, suggestive of a silicate weathering decline. Using a coupled lithium-carbon model, we show that initiation of the glaciation was likely caused by declining $\mathrm{CO}_{2}$ degassing, which triggered abrupt global cooling, and much lower weathering rates. This lower $\mathrm{CO}_{2}$ drawdown during the glaciation allowed climatic recovery and deglaciation. Combined, the data and model provide support from the geological record for the operation of the weathering thermostat.

Received 24 November 2016 | Accepted 15 May 2017 | Published 15 June 2017

\section{Letter}

The recovery and stabilisation of Earth's climate system from perturbations is central to the continued survival of life. Chemical weathering of continental silicate rocks driving marine carbonate precipitation is the Earth's primary longterm mechanism for removal of atmospheric $\mathrm{CO}_{2}$ (Berner, 2003). A temperature

1. London Geochemistry and Isotope Centre, Institute of Earth and Planetary Sciences, University College London and Birkbeck, University of London, Gower Street, London, WC1E 6BT, UK

Corresponding author (email: p.strandmann@ucl.ac.uk)

Department of Earth and Environmental Sciences, University of Ottawa, ON K1N 6N5, Canada

Department of Earth Sciences, University of Oxford, Oxford, OX1 3AN, UK

Chemostrat Ltd, Welshpool, SY21 8SL, UK

School of Earth and Environmental Sciences, University of Portsmouth, Portsmouth, PO1 2UP, UK

Department of Earth Sciences, University of Durham, Durham, DH1 3LE, UK

7. College of Life and Environmental Sciences, University of Exeter, Exeter, EX4 4OE, UK

feedback control on weathering rates (i.e. greater temperatures cause higher weathering rates, removing more $\mathrm{CO}_{2}$ ) would result in a climate-stabilising mechanism. This "weathering thermostat" has long been postulated and assumed in models (Colbourn et al., 2015). However, direct evidence for weathering rate changes in response to climate perturbations has been harder to pin down in the geological record.

The Late Ordovician Hirnantian ( 445 Ma) records the second largest mass extinction in Earth history. This was likely caused by rapidly decreasing temperatures, culminating in an ice-sheet over Gondwana (Elrick et al., 2013). As such, similarities exist between the Hirnantian and the Late Cenozoic glaciations (Ghienne et al., 2014). The behaviour of atmospheric $\mathrm{CO}_{2}$ is of particular interest, because of the potential role of declining $\mathrm{CO}_{2}$ in initiating the glaciation and of increasing $\mathrm{CO}_{2}$ in terminating it (Vandenbroucke et al., 2010). Either or both could have involved changes in silicate weathering rates (Berner, 2003). The combination of changes in weathering rates and $\mathrm{pCO}_{2}$ also resulted in a global positive $\delta^{13} \mathrm{C}$ excursion (HICE) (Lenton et al., 2012; Ghienne et al., 2014). Osmium isotopes have suggested a decline in weathering during the glacial maximum (Finlay et al., 2010). However, Os mainly traces weathering provenance, rather than weathering rates or processes. Lithium isotopes are the only tracer available whose behaviour is solely controlled by silicate weathering processes, and therefore give a unique insight into $\mathrm{CO}_{2}$ drawdown and climate-stabilisation.

Lithium isotopes $\left(\delta^{7} \mathrm{Li}\right)$ are not fractionated by biological processes (Pogge von Strandmann et al., 2016), and are not affected by carbonate weathering (Dellinger et al., 2015). The $\delta^{7} \mathrm{Li}$ of primary silicate rocks defines a narrow range (continental crust $\sim 0.6 \pm 0.6 \%$, basalt $\sim 3-5 \%$; Sauzeat et al., 2015) compared to the high variability in modern rivers (2-44\%o; Huh et al., 1998; Dellinger et al., 2015; Pogge von Strandmann and Henderson, 2015). Riverine values reflect weathering processes, particularly the extent of preferential uptake of ${ }^{6} \mathrm{Li}$ into secondary minerals (Dellinger et al., 2015), and therefore reflect "weathering congruency", defined as the ratio of primary rock dissolution (driving rivers to low, rock-like, $\delta^{7} \mathrm{Li}=$ congruent dissolution of rock), to secondary mineral formation (driving rivers to high $\delta^{7} \mathrm{Li}$; Misra and Froelich, 2012; Pogge von Strandmann and Henderson, 2015). In modern oceans, rivers ( 50\% of the ocean input, with a mean $\delta^{7} \mathrm{Li} \sim 23 \%$; Huh et al., 1998) are combined with mid-ocean ridge hydrothermal solutions ( $50 \%$, with a mean $\delta^{7} \mathrm{Li} \sim 7 \%$; Chan et al., 1993). The oceanic sinks are incorporation into low-temperature clays in altered oceanic basalt (AOC) and marine authigenic clays (MAAC), which cumulatively impose an isotopic fractionation of $\sim 15 \%$, driving modern seawater to $31 \%$. Marine carbonates represent a negligible sink for $\mathrm{Li}$, and their isotopic fractionation factor remains approximately constant at $\sim 3-5 \%$, independent of temperature, salinity, or whether the calcite is inorganic or skeletal (Marriott et al., 2004; Pogge von Strandmann et al., 2013)

Here we present $\delta^{7} \mathrm{Li}$ from bulk carbonates and brachiopods from Anticosti Island, Canada (Achab et al., 2013) (Pointe Laframboise and Ellis Bay West), and from an equivalent shale section at Dob's Linn, UK (Finlay et al., 2010; 
Melchin et al., 2013) (see Supplementary Information for methods and data). The $\delta^{7} \mathrm{Li}$ values from all sections exhibit a positive excursion of $\leq 10 \%$ before the HICE (Fig. 1). We rule out effects on carbonate $\delta^{7} \mathrm{Li}$ by silicate leaching, due to our processing technique (see Supplementary Information). We also rule out diagenesis, because trends and absolute values of $\delta^{7} \mathrm{Li}, \delta^{13} \mathrm{C}$ and $\delta^{18} \mathrm{O}$ (Melchin et al., 2013) are reproduced in different sections, both bulk carbonates and brachiopods (Fig. 1). Overall, therefore, this suggests that the Li isotopic excursion represents a primary seawater signal.

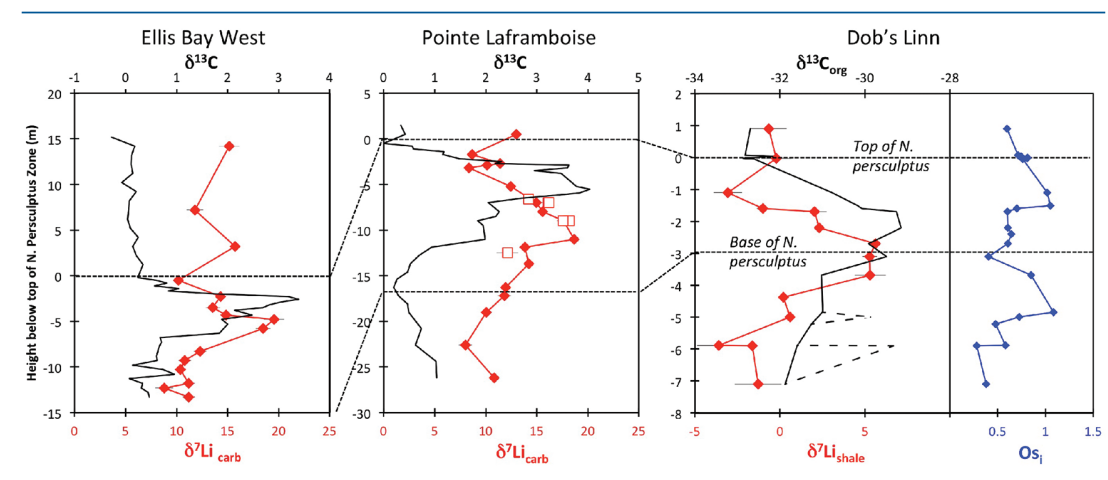

Figure 1 Carbonate (Pointe Laframboise and Ellis Bay West) and shale (Dob's Linn) Li isotope ratios. Open squares are separately analysed brachiopods. Carbon and osmium (initial ${ }^{187} \mathrm{Os} / 188 \mathrm{Os}$ ) isotope data are from the same samples (Finlay et al., 2010). Biostratigraphic correlation is based on the $N$. persculptus Zone (Melchin et al., 2013).

While carbonates tend to be the usual seawater archive (e.g., Misra and Froelich, 2012; Pogge von Strandmann et al., 2013), silicates have also been investigated (Dellinger et al., 2017), and sediments older than Ordovician are considered to represent pre-depositional (unaltered by diagenesis) weathering signals (Li et al., 2016). Hence, detrital clays (which dominate at Dob's Linn) should reflect changing local continental weathering conditions (see Supplementary Information and Fig. S-4). Tracers such as Si/Al, Li/Al or ${ }^{187} \mathrm{Os} /{ }^{188} \mathrm{Os}$ rule out control by changing provenance or clay mineralogy. Dob's Linn exhibits an isotope excursion of similar magnitude, but 14\%o lower than the carbonates. While biostratigraphy suggests that the $\delta^{13} \mathrm{C}_{\mathrm{carb}}$ and $\delta^{13} \mathrm{C}_{\mathrm{org}}$ of Anticosti and Dob's Linn are slightly offset (Melchin et al., 2013) (Fig. 1), in all sections the relative timings of the $\delta^{7} \mathrm{Li}$ and HICE are similar. Chemostratigraphy therefore suggests the $\mathrm{Li}$ isotope excursions occur contemporaneously (see Supplementary Information), consistent with lithium's long modern ocean residence time ( 1 Myr). A simple temperature dependence of the clay fractionation factor during weathering would only cause $<1.6 \%$ variation ( $\mathrm{Li}$ and West, 2014), and is therefore not the cause of the observed variability. Although shales, in particular clay fractionation factors, are under-constrained for a quantitative interpretation in isolation, their comparison to and temporal similarities with carbonates suggests a link.
Thus, global seawater compositions (represented by carbonates) appear to be responding to the same driving force as this local archive of continental weathering (represented by shales).

The pre- and post-excursion $\delta^{7} \mathrm{Li}_{\text {seawater }}$ values of $\sim 15 \%$ are difficult to achieve in a modern ocean. It is likely that the AOC and MAAC sinks were broadly similar to today (Hazen et al., 2013), imparting an isotopic fractionation factor of $15 \%$, which may be temperature-dependent, as discussed below. We do not consider a "sink-shift" between proportions of MAAC vs. AOC, as proposed for the Cenozoic (Li and West, 2014), because the Hirnantian duration is likely too short (1-2 Myr) for a transient change. Therefore, Li inputs must have had an isotope ratio close to $0 \%$. Assuming a modern-like hydrothermal input, this requires that rivers had $\delta^{7} \mathrm{Li}$ values essentially unfractionated from the continental crust (modern value $\sim 0 \%$; Sauzeat et al., 2015). This possibility is supported by $\delta^{7} \mathrm{Li}$ values of $\sim 2 \%$ for the Amazon river (Dellinger et al., 2015), and similarly low values during the peak of the Cenomanian-Turonian hyperthermal (Pogge von Strandmann et al., 2013). However, data here imply that Ordovician oceans were isotopically light at steady state. Given that the first non-vascular land plants were only just evolving and colonising the continents in the midlate Ordovician (with associated organic acid production), it is probable that clay types were different and less abundant (Hazen et al., 2013). For example, illites, which cause little Li isotope fractionation (Millot and Girard, 2007), are thought to dominate prior to terrestrialisation by plants (Hazen et al., 2013). If this is a feature of early Earth weathering, then the continental crust's $\delta^{7} \mathrm{Li}$ would have been mantle-like $(\sim 3 \%$ o), rather than driven isotopically light by weathering.

Assuming, therefore, that silicate weathering was highly congruent, we have created a dynamic non-steady state coupled Li and C cycle model (see Supplementary Information). In brief, the model uses Li formulations from previous work (Pogge von Strandmann et al., 2013; Lechler et al., 2015), with an added temperature dependence on the Li sink with a sensitivity of $-0.15 \%$ o $/ \mathrm{K}$ ( Li and West, 2014), and links the weathering flux to that calculated by the carbon cycle model (based on GEOCARB III). Existing climate models suggest that $\mathrm{pCO}_{2}$ needed to halve to 8 PAL (present atmospheric level) to trigger the Hirnantian glaciation (Pohl et al., 2016). This could be initiated by a decline in degassing (McKenzie et al., 2016), an increase in plant cover (Lenton et al., 2012) or uplift (Kump et al., 1999), or a combination of these. A rather extreme decline in degassing from the initial Ordovician value of $1.55 \times$ to $0.75 \times$ modern causes $\mathrm{CO}_{2}$ to drop to 6.5 PAL. Both the hydrothermal and riverine Li fluxes scale proportionally to degassing, resulting in no steady state change, but a transient adjustment of the oceanic Li reservoir causes a positive $\delta^{7} \mathrm{Li}$ excursion of $\sim 3.5 \%$ o (i.e. correct direction, but smaller excursion). In contrast, increasing plant-induced weathering (and associated clay mineral formation) causes a permanent, rather than transient $\delta^{7} \mathrm{Li}$ increase (see Supplementary Information), which is not observed in our data. However, it is possible that the two processes operated in conjunction. A $65 \%$ increase in uplift would create the same effect, but would be unprecedented in the Phanerozoic. Theoretically, the excursion could also be caused by 
an increase in riverine $\delta^{7} \mathrm{Li}$ by $\sim 15 \%$ with no change in flux. However this is unlikely, because it implies greater uptake into clay minerals, which would cause a decrease in river flux. This scenario also has no carbon cycle forcing, and hence we prefer a coupled flux and isotope ratio change, initiated by a degassing change.

A recent insight is that a glacial "tipping point" existed in the Late Ordovician, where, once global temperature dropped to a critical threshold, northern high latitude sea-ice expanded abruptly, causing a further decrease in global temperatures and rapid expansion of an ice sheet on the Southern polar land surfaces (Pohl et al., 2016). These ice albedo and heat transport feedbacks operate far faster than the long-term carbon cycle. Hence to represent this we implement an abrupt cooling when $\mathrm{CO}_{2}$ reaches $\sim 8 \mathrm{PAL}$, generating reduced silicate weathering rates. To prevent an immediate abrupt warming, we assume some bi-stability of temperature and ice cover such that $\mathrm{CO}_{2}$ has to rise to $>8 \mathrm{PAL}$ before deglaciation occurs. The cooling-induced reduction in global weathering flux (by $\sim 4 \times$ ), causes an accelerated rise in $\delta^{7} \mathrm{Li}$ from 17-19\%o (depending on continental crust composition) to $>25 \%$ (Fig. 2), which is reversed when the build-up of $\mathrm{CO}_{2}$ triggers abrupt warming and deglaciation. Hence peak $\delta^{7} \mathrm{Li}$ is predicted to be at the end of the glacial interval, consistent with sea-level reconstructions (Fig. 2). The size of the excursion could be increased by coupling the weathering decline with higher riverine $\delta^{7} \mathrm{Li}$, as suggested by the shale record (Fig. 2). This could be caused by an increase in the continental residence time of water allowing more clay formation, or a temperature-dependent shift in clay mineralogy. Such a change in congruency could also assist a vegetationaccelerated scenario, where terrestrialisation enhanced weathering, but enhanced glacial grinding forced a return to more congruent weathering. Such vegetative forcing would also cause a transient $\delta^{7} \mathrm{Li}$ excursion (Fig. S-9), albeit one of longer duration, hence we consider this less likely. Critically, the model can explain an increase in $\delta^{7} \mathrm{Li}$ as cooling starts, but before the full glaciation was initiated, and the highest oceanic $\delta^{7} \mathrm{Li}$ occurring at the end of the glaciation as observed in the record. ${ }^{187} \mathrm{Os} /{ }^{188} \mathrm{Os}$ values (Finlay et al., 2010) agree with this scenario, suggesting inhibition of weathering by cooling (which would also increase $\mathrm{CO}_{2}$; Kump et al., 1999) and hence a change in provenance focus, coincident with the $\delta^{7} \mathrm{Li}$ peak Our model also predicts ${ }^{87} \mathrm{Sr} /{ }^{86} \mathrm{Sr}$ variation within the observed scatter (Shields et al., 2003), lending further credence to our interpretation (see Supplementary Information).

The data and model are therefore consistent with the Hirnantian glaciation being initiated by declining $\mathrm{CO}_{2}$ degassing, leading to a transient decline in silicate weathering, in turn causing an atmospheric $\mathrm{CO}_{2}$ increase that ultimately terminated the glaciation. The Hirnantian has been compared to Cenozoic glaciations (Ghienne et al., 2014), where both periods are now characterised by increasing $\delta^{7} \mathrm{Li}$ values (Misra and Froelich, 2012). The positive $\delta^{7} \mathrm{Li}$ excursion during the Hirnantian cooling event also compares well to negative $\delta^{7} \mathrm{Li}$ excursions during warming events (Pogge von Strandmann et al., 2013; Lechler et al., 2015). Overall, therefore, this study shows that if a tectonic-driven climate control (degassing) can push the climate system out of balance, a temperature-dependent

feedback via silicate weathering will eventually stabilise the climate. Such a weathering thermostat has frequently been postulated as a climate regulating process, but has proven remarkably difficult to unambiguously demonstrate in the geological record.



Sealevel $\delta$

Figure 2 Comparison of data and model results. Sea level timing is from stratigraphic data (Ghienne et al., 2014). Seawater Li isotope data were generated from carbonate data by adding a $4 \%$ fractionation factor (Marriott et al., 2004). The model shows the changes in riverine and hydrothermal Li fluxes, the $\mathrm{pCO}_{2}$ levels and temperature anomalies caused by these changes, and the resulting oceanic $\delta^{\prime} \mathrm{Li}$ curve. The red model lines are for scenarios where riverine $\delta^{7} \mathrm{Li}$ $=3 \%, 0 \%$, a change from 0 to $10 \%$ during the glaciation and "shale-constrained" (s.c.), using Dob's Linn $\delta^{7} \mathrm{Li}$ data to constrain river values (see text and Supplementary Information for detail)

\section{Acknowledgements}

This study and PPvS were funded by NERC advanced research fellowship NE/ I020571/2 and ERC Consolidator grant 682760 - CONTROLPASTCO2. AD thanks the support of the Natural Science and Engineering Council of Canada (Discovery Grant). TML was supported by NERC (NE/N018508/1). DS acknowledges the Total Endowment Fund. Michael Melchin is thanked for reading an earlier version of the manuscript. This manuscript was greatly improved by reviews from Lee Kump, Jerome Gaillardet and an anonymous reviewer.

Editor: Liane G. Benning

\section{Author Contributions}

PPvS wrote the research proposal, carried out the analyses and wrote the manuscript. TML and PPvS conducted the modelling. AD, AJF and DS provided samples, geochemical context and edited the manuscript. MJM assisted in analyses and edited the manuscript. 


\section{Additional Information}

Supplementary Information accompanies this letter at www.geochemicalperspectivesletters.org/article1726

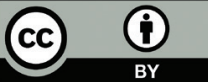

his work is distributed under the Creative Commons Attribution 4.0 License, which permits unrestricted use, distribution, and reproduction in any medium, provided the original author and source are credited. Additional information is available at http://www. geochemicalperspectivesletters.org/copyright-and-permissions.

Cite this letter as: Pogge von Strandmann, P.A.E. , Desrochers, A., Murphy, M.J., Finlay, A.J., Selby, D., Lenton, T.M. (2017) Global climate stabilisation by chemica weathering during the Hirnantian glaciation. Geochem. Persp. Let. 3, 230-237.

\section{References}

Achab, A., Asselin, E., Desrochers, A., Riva, J.F. (2013) The end-Ordovician chitinozoan zone of Anticosti Island, Quebec: Definition and stratigraphic position. Review of Palaeobotany and Palynology 198, 92-109.

BERNER, R.A. (2003) The long-term carbon cycle, fossil fuels and atmospheric composition. Nature $426,323-326$.

Chan, L.H., Edmond, J.M., Thompson, G. (1993) A lithium isotope study of hot springs and metabasalts from mid-ocean ridge hydrothermal systems. Journal of Geophysical Research 98, 9653-9659.

Colbourn, G., RidgWelL, A., Lenton, T.M. (2015) The time scale of the silicate weathering negative feedback on atmospheric CO2. Global Biogeochemical Cycles 29, 583-596.

Dellinger, M., Gaillardet, J., Bouchez, J., Calmels, D., Louvat, P., Dosseto, A., Gorge, C., Alanoca, L., Maurice, L. (2015) Riverine Li isotope fractionation in the Amazon River basin controlled by the weathering regimes. Geochimica et Cosmochimica Acta 164, 71-93.

Dellinger, M., Bouchez, J., Gaillardet, J., Faure, L., Moureau, J. (2017) Tracing weathering regimes using the lithium isotope composition of detrital sediments. Geology 45, 411-414.

Elrick, M., Reardon, D., Labor, W., Martin, J., Desrochers, A., Pope, M. (2013) Orbitalscale climate change and glacioeustasy during the early Late Ordovician (pre-Hirnantian)

Finlay, A.J., SelBY, D., GROCKE, D.R. (2010) Tracking the Hirnantian glaciation using Os isotopes Earth and Planetary Science Letters 293, 339-348.

Ghienne, J.-F., Desrochers, A., Vandenbroucke, T.R.A., Achab, A., Asselin, E., Dabard, M.-P., Farley, C., Loi, A., Paris, F., Wickson, S., Veizer, J. (2014) A Cenozoic-style scenario for the end-Ordovician glaciation. Nature Communications 5, doi: 10.1038/ncomms5485.

Hazen, R.M., Sverjensky, D.A., Azzolini, D., Bish, D.L., Elmore, S.C., Hinnov, L., Milliken, R.E. (2013) Clay mineral evolution. American Mineralogist 98, 2007-2029.

HuH, Y., CHAN, L.H., ZHANG, L., EDMOND, J.M. (1998) Lithium and its isotopes in major world rivers: Implications for weathering and the oceanic budget. Geochimica et Cosmochimica Acta 62, 2039-2051.

Kump, L.R., Arthur, M.A., PatzKowsky, M.E., Gibbs, M.T., Pinkus, D.S., Sheehan, P.M. (1999) A weathering hypothesis for glaciation at high atmospheric pCO2 during the Late Ordovician. Palaeogeography, Palaeoclimatology, Palaeoecology 152, 173-187.
Lechler, M., Pogge von Strandmann, P.A.E., Jenkyns, H.C., Prosser, G., Parente, M. (2015) Lithium-isotope evidence for enhanced silicate weathering during OAE 1a (Early Aptian Selli event). Earth and Planetary Science Letters 432, 210-222.

Lenton, T.M., Crouch, M., Johson, M., Pires, N., Dolan, L. (2012) First plants cooled the Ordovician. Nature Geoscience 5, 86-89.

LI, G., WeST, A.J. (2014) Evolution of Cenozoic seawater lithium isotopes: Coupling of global denudation regime and shifting seawater sinks. Earth and Planetary Science Letters 401, 284-293.

LI, S., GASCHNIG, R.M., RUDNICK, R.L. (2016) Insights into chemical weathering of the upper continental crust from the geochemistry of ancient glacial diamictites. Geochimica et Cosmochimica Acta 176, 96-117.

Marriott, C.S., Henderson, G.M., Crompton, R., Staubwasser, M., Shaw, S. (2004) Effect of mineralogy, salinity, and temperature on $\mathrm{Li} / \mathrm{Ca}$ and $\mathrm{Li}$ isotope composition of calcium carbonate. Chemical Geology 212, 5-15.

McKenzie, N.R., Horton, B.K., Loomis, S.E., Stockli, D.F., Planavsky, N.J., Lee, C.-T.A. (2016) Continental arc volcanism as the principal driver of icehouse-greenhouse variability. Science 352, 444-447.

Melchin, M.J., Mitchell, C.E., Holmden, C., Storch, P. (2013) Environmental changes in the Late Ordovician-early Silurian: Review and new insights from black shales and nitrogen isotopes. Geological Society of America Bulletin 125, 1635-1670.

Millot, R., GIRARD, J.P. (2007) Lithium Isotope Fractionation during adsorption onto minera surfaces. International Meeting: Clays in Natural \& Engineered Barriers for Radioactive Waste Confinement (Lille, France).

MisRA, S., Froelich, P.N. (2012) Lithium Isotope History of Cenozoic Seawater: Changes in Silicate Weathering and Reverse Weathering. Science 335, 818-823.

Pogge von Strandmann, P.A.E., Henderson, G.M. (2015) The Li isotope response to mountain uplift. Geology 43, 67-70.

Pogge von Strandmann, P.A.E., Jenkyns, H.C., Woodfine, R.G. (2013) Lithium isotop evidence for enhanced weathering during Oceanic Anoxic Event 2. Nature Geoscience 6, 668-672.

Pogge von Strandmann, P.A.E., Burton, K.W., Opfergelt, S., Eiriksdottir, E.S., Murphy, M.J., EINARSSON, A., GisLason, S.R. (2016) The effect of hydrothermal spring weathering processes and primary productivity on lithium isotopes: Lake Myvatn, Iceland. Chemical Geology 445, 4-13.

Pohl, A, Donnadieu, Y, Le Hir, G, Ladant, J-B, Dumas, C, Alvarez-Solas, J, VandenBROUCKE, T.R.A. (2016) Glacial onset predated Late Ordovician climate cooling. Paleoceanography 31, 800-821.

Sauzeat, L., Rudnick, R.L., Chauvel, C., Garcon, M., TANG, M. (2015) New perspectives on the Li isotopic composition of the upper continental crust and its weathering signature. Earth and Planetary Science Letters 428, 181-192.

Shields, G.A., CARDEn, G.A.F., Veizer, J., Meidla, T., Rong, J.-Y., LI, R.-Y. (2003) Sr, C, and O isotope geochemistry of Ordovician brachiopods: A major isotopic event around the MiddleLate Ordovician transition Geochimica et Cosmochimica Acta 67, 2005-2025.

Vandenbroucke, T.R.A., Armstrong, H.A., Williams, M., Paris, F., Zalasiewicz, J.A., Sabbe, K., Nolvak, J., Challandsa, T.J., Verniers, J., Servais, T. (2010) Polar front shift nd atmospheric $\mathrm{CO} 2$ during the glacial maximum of the Early Paleozoic Icehouse. Proceedings of the National Academy of Sciences of the United States of America 107, 14983-1498 